\title{
The role of electric vehicles in near-term mitigation pathways and achieving the UK's carbon budget
}

\author{
Graeme Hill $^{\mathrm{a}, *}$, Oliver Heidrich ${ }^{\mathrm{b}}$, Felix Creutzig ${ }^{\mathrm{c}, \mathrm{d}}$, Phil Blythe ${ }^{\mathrm{a}}$ \\ ${ }^{a}$ School of Engineering, Systems for Future Mobility, Newcastle University, Newcastle upon Tyne NE1 7RU, UK \\ ${ }^{\mathrm{b}}$ School of Engineering, Tyndall Centre for Climate Change Research, Newcastle University, Newcastle upon Tyne NE1 7RU, UK \\ ${ }^{\mathrm{c}}$ Mercator Research Institute on Global Commons and Climate Change, Torgauer Str. 12-15, 10829 Berlin, Germany \\ ${ }^{\mathrm{d}}$ Sustainability Economics of Human Settlements, Technical University Berlin, Straße des 17. Juni 135, 10623 Berlin, Germany
}

\section{H I G H L I G H T S}

- An accelerated EV program is needed to meet $2050 \mathrm{CO} 2$ emission targets for the UK.

- Even under accelerated uptake, few $\mathrm{CO}_{2}$ benefits will be seen before 2030 .

- The lack of impact before 2030 derives from slow vehicle stock turnover.

- With embedded production CO2, 2050 UK targets will need intense grid decarbonisation.

- There is an urgent need to pursue both EV uptake and demand side solutions.

\section{A R T I C L E I N F O}

\section{Keywords:}

Electric vehicles

Vehicle ownership

Vehicle production

Stock flow model

Climate change mitigation

\begin{abstract}
A B S T R A C T
The decarbonisation of the road transport sector is increasingly seen as a necessary component to meet global and national targets as specified in the Paris Agreement. It may be achieved best by shifting from Internal Combustion Engine (ICE) cars to Electric Vehicles (EVs). However, the transition to a low carbon mode of transport will not be instantaneous and any policy or technological change implemented now will take years to have the desired effect. Within this paper we show how on-road emission factors of EVs and models of embedded $\mathrm{CO}_{2}$ in the vehicle production may be combined with statistics for vehicle uptake/replacement to forecast future transport emissions. We demonstrate that EVs, when compared to an efficient ICE, provide few benefits in terms of $\mathrm{CO}_{2}$ mitigation until 2030. However, between 2030 and 2050, predicted $\mathrm{CO}_{2}$ savings under the different EV uptake and decarbonisation scenarios begin to diverge with larger $\mathrm{CO}_{2}$ savings seen for the accelerated EV uptake. This work shows that simply focusing on on-road emissions is insufficient to model the future $\mathrm{CO}_{2}$ impact of transport. Instead a more complete production calculation must be combined with an EV uptake model. Using this extended model, our scenarios show how the lack of difference between a Business as Usual and accelerated EV uptake scenario can be explained by the time-lag in cause and effect between policy changes and the desired change in the vehicle fleet. Our work reveals that current UK policy is unlikely to achieve the desired reduction in transport-based $\mathrm{CO}_{2}$ by 2030. If embedded $\mathrm{CO}_{2}$ is included as part of the transport emissions sector, then all possible UK EV scenarios will miss the reduction target for 2050 unless this is combined with intense decarbonisation ( $80 \%$ of 1990 levels) of the UK electricity grid. This result highlights that whilst EVs offer an important contribution to decarbonisation in the transport sector it will be necessary to look at other transport mitigation strategies, such as modal shift to public transit, car sharing and demand management, to achieve both near-term and long-term mitigation targets.
\end{abstract}

\section{Introduction}

The transport sector has been identified as a key barrier to decarbonisation based on the high costs of substituting energy-dense liquid fossil fuels [1,2]. A potential solution is in the transition to electromobility, and more specifically a shift from gasoline and diesel cars to electric vehicles (EVs). Previous research has demonstrated that EVs offer the potential for large scale reduction in carbon dioxide $\left(\mathrm{CO}_{2}\right)$

\footnotetext{
* Corresponding author.

E-mail addresses: g.a.hill@ncl.ac.uk (G. Hill), Oliver.Heidrich@ncl.ac.uk (O. Heidrich), Creutzig@mcc-berlin.net (F. Creutzig), phil.blythe@ncl.ac.uk (P. Blythe).
} 
emissions from the transport sector. The assertion that EVs can deliver high $\mathrm{CO}_{2}$ emissions reductions requires better underpinning of detailed national or regional studies that are informed both by empirical and conceptual detail. The UK, which consists of four countries: England, Wales, Northern Ireland and Scotland covering an area of $243,610 \mathrm{~km}^{2}$ and an estimated population of about 62 million people, offers itself as an attractive case study due to its generally progressive climate policies $[3,4]$ and insular location, which reduces dependencies on international and transit road users. In 2008, the Climate Change Act 2008 [5] was introduced in the UK with the stated aim of reducing UK greenhouse gas (GHG) emissions to $80 \%$ of the 1990 levels by 2050 . The Committee of Climate Change [6] estimated that transport is one of the largest $\mathrm{CO}_{2}$ emitters in the UK, with emissions in 2016 amounting to $26 \%$ of the total GHG emissions. However, contrasting with substantial reductions in other sectors, the transport sector has stagnated with the total emitted $\mathrm{CO}_{2}$ remaining approximately equivalent to 1990 levels, without any apparent signs of improvement. [7]

As road transport makes up $91 \%$ of domestic transport emissions with cars and taxis accounting for $56 \%$ of all transport $\mathrm{CO}_{2}$ emissions in 2016 [8], one climate change mitigation strategy within the UK is to focus on a shift to EVs in the passenger car fleet. To facilitate this the UK Government has published the Policy Paper 'Clean Growth Strategy' [9], which has described the role EVs will play in both driving and decarbonising the UK economy, in addition to the 'Road to Zero' policy paper [10]. EV ownership increased by $180 \%$ in 2017 with 53,000 newly registered vehicles, or $1.7 \%$ of all newly registered vehicles [11]. Whilst this demonstrates a continued increase in EV purchase rates, it is clear a bigger shift is needed to achieve $2050 \mathrm{CO}_{2}$ emission reduction targets, with the Committee for Climate Change [12] estimating that by 2030 some $60 \%$ of all newly registered vehicles will need to be an EV.

The fundamental goal of this research is to examine whether the UK's EV adoption policy, coupled with the likely technological changes and vehicle transition models, will allow the UK to meet the transport $\mathrm{CO}_{2}$ emission targets in both the near-term (2018-2030), and mid-term (2030-2050) timescales. This is achieved through investigating the climate mitigation effects of electrifying the UK's passenger automobile fleet, including emissions from both car usage and vehicle production and including the likely timescales for the transition to EVs from ICE vehicles.

Previous work has looked at the impact of EV adoption on reducing $\mathrm{CO}_{2}$ emissions [13-15] and the impact on materials usage [16], including possible forthcoming shortages in the necessary materials for large scale EV adoption [17]. However this paper shows how embedded $\mathrm{CO}_{2}$, which is defined in this paper as the $\mathrm{CO}_{2}$ emitted during the production of vehicles, coupled with actual vehicle adoption data may be used to determine the overall impact of EV adoption on the $\mathrm{CO}_{2}$ footprint of the transport sector within the UK. More specifically, we examine how the UK may, or may not, meet the transport emission targets for $\mathrm{CO}_{2}$ reduction set out in the Climate Change Act 2008 [5] and how the inclusion of embedded $\mathrm{CO}_{2}$ will affect the overall emission reduction.

We show that even with accelerated EV adoption ambitions, the volume of EVs and thus their impact on $\mathrm{CO}_{2}$ emissions reduction, will remain comparatively low until at least 2030 . However, we provide evidence that post 2030, under all EV adoption scenarios, the volume of EVs and their cumulative $\mathrm{CO}_{2}$ emission reductions will begin to substantially increase. It will thus become necessary for cities, regions, and countries to implement a dedicated EV policy framework designed to facilitate the transition to a low $\mathrm{CO}_{2}$ emission passenger transport fleet in the mid-term, but also to draw on other options, such as modal shift and incentivized telecommuting, to reach the UK's near-term $\mathrm{CO}_{2}$ emission mitigation targets. accounted for $1080 \mathrm{MtCO}_{2} \mathrm{e}$ (the total weight of $\mathrm{CO}_{2}$ which would have an equivalent global warming potential) and contributed $27 \%$ to the total GHG emissions across EU-28 countries [18]. Notably, it is the only sector which has seen a rise of GHG emissions compared to 1990 levels. This increasing share of GHG emissions from the transport sector follows a structural change dynamic, where the shift of economies from industry to services corresponds to a rise of transport intensity in energy use $[19,20]$. It is however also rooted in a supply/demand game of making vehicles increasingly powerful and heavier thus compensating for gains in technological efficiency [21]. The EU has developed a range of policies in order to mitigate the effects from transport on climate change with the majority aimed at reducing $\mathrm{CO}_{2}$ emissions, and hence reducing total GHG emissions:

- $\mathrm{CO}_{2}$ emissions for new cars and vans: Car manufacturers have to ensure that their new car fleet does not emit more than an average of $130 \mathrm{~g} \mathrm{CO}_{2} / \mathrm{km}$ by 2015 and $95 \mathrm{~g} \mathrm{CO}_{2} / \mathrm{km}$ by 2020 . Recent regulation proposals [22] have improved this to $67 \mathrm{gCO}_{2} / \mathrm{km}$ by 2030 , a reduction of $30 \%$ over the 2020 levels.

- $\mathrm{CO}_{2}$ labelling of cars: EU legislation ensures that consumers are informed about the fuel efficiency and $\mathrm{CO}_{2}$ emissions for new cars. - Fuel quality: EU legislation requires the GHG intensity of vehicle fuels to be cut by up to $10 \%$ by 2020 .

Actions and inactions by central, regional, and local governments will have profound effects as cities across Europe introduce mitigation strategies to tackle the causes of climate change $[3,23]$. The European Parliament has committed commits its member states to an ambitious climate change strategy reducing GHG emissions and energy consumption by at least $20 \%$ by 2020 using a 1990 baseline [24].

Importantly, the EU points to cities and local authorities as key authorities to help the transition to low-carbon road transport. Local actions explicitly includes the promotion of active travel, mode shift to public transport, and schemes to reduce congestion. Cities can adopt a full spectrum of policies available to promote low-carbon road transport at local scale that involve procurement of electric vehicles, stringent parking management, and the expansion of comfortable and safe bike lanes. Importantly, many (but not all) of these policies can be implemented within short time scales, and have immediate impact on daily routines and travel choices. They may hence complement EU wide action and provide near-team starting points for reducing transport $\mathrm{CO}_{2}$ emissions on the demand side.

\subsection{EVs and national climate change mitigation targets}

EVs have two major characteristics that render them key candidates as new car technology. First, they can be charged with electricity from low or non- $\mathrm{CO}_{2}$ emitting sources, which enables deeper decarbonisation than for vehicles powered by biofuels [25].

Second, electric engines are vastly more efficient than ICEs or other proposed technologies, such as compressed-air cars [26].

A study of the US car industry showed that EVs were a relatively small market, lacking governmental guidance and policies with little motivation for car-makers to accelerate their strategies away from ICE technology [27]. However, a more recent review [28] has shown a strong causal link between EV incentives and EV uptake, indicating a growing market. In order to make road transport more sustainable, the UK Government has promoted the uptake of ultra-low carbon vehicles such as EVs, hydrogen powered vehicles, and vehicles powered by biofuels [29] and to promote economic growth and to cut $\mathrm{CO}_{2}$ emissions across England [30].

\subsection{Transport sector $G H G$ emissions}

In 2016 the transport sector, including international aviation, 


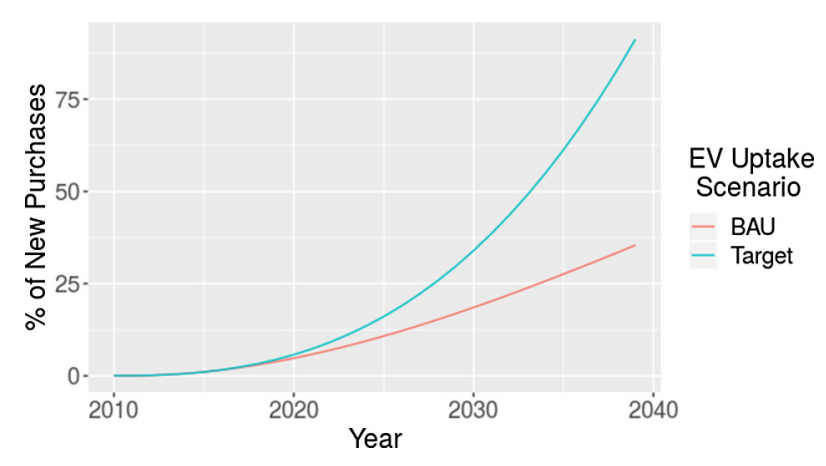

Fig. 1. Comparison of Business as Usual and 2040 EV Adoption Target Scenarios, 2010-2040.

\section{Research data and methodology}

\subsection{Calculating vehicle stock turnover and UK EV adoption rates}

The UK Committee on Climate Change surface transport $\mathrm{CO}_{2}$ abatement scenario from the fifth carbon budget [31] posits that EV sales should reach $60 \%$ of all new car sales by 2030 , which would require a growth rate in annual purchases of $33 \%$.

This, combined with the introduction of a ban on the sale of new petrol and diesel passenger cars and small vans in 2040 by the UK government in 2017 [32] has allowed the creation of a series of predictions on the expected EV adoption rate within the UK, which would be required to meet this target. By extrapolating to the 2040 target from existing EV sales rates, which show an increase of 2074 in 2011 up to 5300 in 2017 [11], it is possible to predict EV sales up to 2040. This prediction for EV car sales is shown in Fig. 1 along with a "Business as Usual" case which assumes that current trends in EV sales will dominate future rates [33].

To understand the impact of EV penetration, and the possible consequences of policies dealing with $\mathrm{EV}$ purchases, it is necessary to understand how EV penetration will affect the passenger vehicle population. The effective in-use $\mathrm{CO}_{2}$ footprint of a vehicle fleet will be determined by the age of the fleet, the distribution of different vehicle fuel-types and the annual mileage for the combination of these two variables.

The UK Road Traffic Forecasts 2015 [34] predict that the expected number of cars in the UK will grow from $25 \mathrm{~m}$ in 2010 to approximately $35 \mathrm{~m}$ in 2040. Therefore, to determine the vehicle population it is necessary to apply the scrappage rate to the vehicle population and then allow a new vehicle purchase level which will match the predicted total car numbers. This may be described as:

$\Delta V=P-S V$

where $\mathrm{V}$ is the vehicle population, $\mathrm{P}$ is the purchase rate and $\mathrm{S}$ is the scrappage rate. The vehicle population can be expanded into a more complete form.

$V^{y}=\sum_{a=a g e} V_{a}^{y}$

where $\mathrm{V}^{y}$ is the total number of vehicles in year $\mathrm{y}$ and $V_{a}^{y}$ is the number of vehicles in year $\mathrm{y}$ of age a.

$V^{y+1}=\alpha P^{y+1}+\sum_{a} V_{a}^{y}\left(1-\beta S_{a}\right)$

Combining (1) and (2) gives (3) where $P^{y+1}$ is the purchase rate in year $y+1, S_{a}$ is the scrappage rate for a vehicle of age a. $\alpha$ and $\beta$ are "balancing" variables to allow the change in vehicle numbers to match our predicted numbers.

The scrappage rate is derived from a road worthiness test, the UK Ministry of Transport test, conducted annually for each vehicle in the UK. The data is collated and released in an anonymised form by the UK
Department for Transport [35]. Contained within the dataset is the result of each road worthiness test, including a unique vehicle ID which allows vehicles to be tracked in subsequent years and only disappears from the dataset when that vehicle is scrapped or otherwise taken offroad. Previous work [36] has used this data to explore spatial and social variations in car usage but here it is used to determine the probability of a vehicle being scrapped and also the initial age profile of all vehicles in the UK. Due to the lack of vehicle import/export between the UK and other countries it is possible to deal with the UK vehicle fleet as an isolated vehicle population.

It is further possible to split the vehicle population by fuel-type (diesel, petrol, electric).

$V_{f}^{y+1}=\alpha P_{f}^{y+1}+\sum_{a} V_{a, f}^{y}\left(1-\beta S_{a, f}\right)$

Here f represents the fuel type with the following constraint.

$\sum_{f=\text { fueltype }} V_{f}^{y}=\sum_{f=\text { fueltype }} \sum_{a=\text { age }} V_{a, f}^{y}$

Finally, it is possible to calculate the total on-road emissions via:-

$E m^{y}=\sum_{a, f} V_{a, f}^{y} M_{a, f}^{y} E_{a, f}^{y}$

Where $M_{a, f}^{y}$ represents the total distance travelled for a vehicle of fuel type f, age a and in year y and $E_{a, f}^{y}$ represents the emission rating for a given vehicle of fuel type $f$, age a and in year $y$.

\subsection{Calculating $\mathrm{UK}$ embedded $\mathrm{CO}_{2}$ emissions for vehicle manufacturing}

In addition to the on-road $\mathrm{CO}_{2}$ emissions it is also necessary to calculate the embedded $\mathrm{CO}_{2}$ from vehicle production. EVs are typically a more resource intensive vehicle at the original manufacture point, and ignoring the $\mathrm{CO}_{2}$ emitted during their production will artificially inflate their environmental benefit over traditional vehicles.

The embedded $\mathrm{CO}_{2}$ will be given by the number of new vehicles produced in any given year for each specific fuel type and can be calculated for each year as:

$E m b^{y}=\sum_{f} V_{a=0, f}^{y} P C_{f}^{y}$

In Eq. (7) $P C_{f}^{y}$ is the $\mathrm{CO}_{2}$ produced in the manufacture of a vehicle with fuel type $\mathrm{f}$ in year $\mathrm{y} \cdot V_{a=0, f}^{y}$ is the national number of vehicles of fuel type $f$, with age 0 in year $y$.

\subsection{On-road $\mathrm{CO}_{2}$ emissions from EVs and ICES}

If EVs are to be a possible solution for reducing $\mathrm{CO}_{2}$ emissions from the transport sector, then it must be shown that EVs will deliver a net reduction of $\mathrm{CO}_{2}$ emissions if they replace internal combustion engine (ICE) vehicles on a like for like basis.

In SwitchEV, a large scale EV deployment and assessment research project within the UK $[37,38]$, the installation of loggers on $44 \mathrm{EVs}$ allowed for the collection of real world data, which included driving behaviour and vehicle recharging events. From the time of each recharge event it was possible to assign a $\mathrm{gCO}_{2} / \mathrm{kWh}$ value to the energy being stored in an EV battery. This value is derived from the power mix used to generate the electricity at the time of charge. When on a journey, the energy used by the vehicle is monitored so an average $\mathrm{gCO}_{2} / \mathrm{km}$ travelled could be assigned to a particular trip.

Fig. 2 shows the average $\mathrm{gCO}_{2} / \mathrm{km}$ for all trips. The average for the whole logged EV fleet during the period 2011-2013 was $85 \mathrm{~g} \mathrm{CO}_{2} / \mathrm{km}$. This number was originally calculated using the 2011-2013 carbon intensity but assuming the same trip/charging patterns it can be shown that under the 2017 carbon intensity the average $\mathrm{gCO}_{2} / \mathrm{km}$ would drop to $43 \mathrm{gCO}_{2} / \mathrm{km}$. In the UK in 2010 the new car average was $140 \mathrm{gCO}_{2} /$ $\mathrm{km}$ and in 2015 the Society of Motor Manufacturers and Traders (SMMT) has reported that this is now down to $121 \mathrm{gCO}_{2} / \mathrm{km}$. The published figures from the SMMT were originally calculated based on 


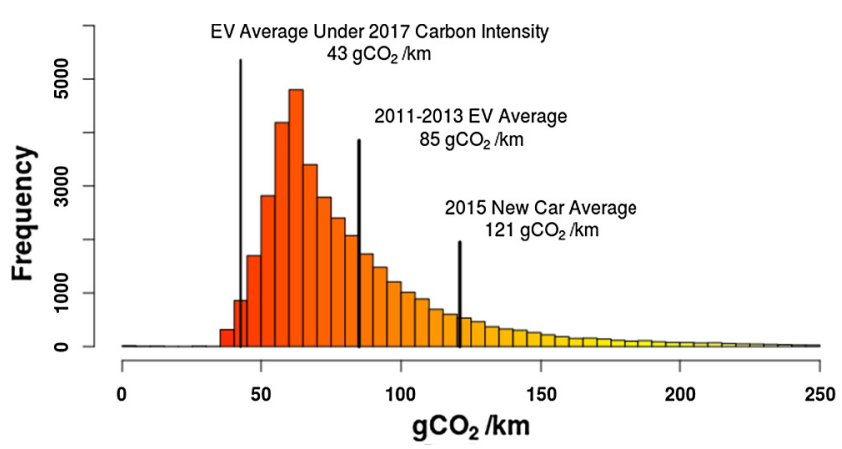

Fig. 2. Distribution of the $\mathrm{CO}_{2} / \mathrm{km}$ for $63,000 \mathrm{EV}$ journeys plus the average efficiency under 2011-2013 and 2017 carbon intensity. Also shown, the comparative values for an average new car in 2015.

the assumption that the stated fleet efficiencies are correct when in reality they are likely to be underestimated by 30-40\% [39]. Currently the targets are based on the stated fleet efficiencies, rather than actual $\mathrm{CO}_{2}$ emissions. Therefore, if calculations going forward are based on the actual $\mathrm{CO}_{2}$ emissions, then the ability of the fleet to hit the intended targets will be substantially impeded.

\subsection{Embedded $\mathrm{CO}_{2}$ emissions from vehicle manufacture}

The full $\mathrm{CO}_{2}$ emissions associated with an $\mathrm{EV}$ will also include the $\mathrm{CO}_{2}$ produced during its manufacture as well as those produced during the car's lifetime. For the UK, the most comprehensive report on production-related $\mathrm{CO}_{2}$ emissions from the manufacture of EVs and ICEs was published by Ricardo [40]. The report found that production in the UK of a standard mid-sized ICE will result in emissions of $5.6 \mathrm{tCO}_{2}$, whilst production of an equivalent sized $\mathrm{EV}$ will result in $\mathrm{CO} 2$ emissions of $8.8 \mathrm{tCO}_{2}$.

The exact amount of $\mathrm{CO}_{2}$ emissions from production of both ICEs and EVs is a matter of some dispute with a wide range of possible figures depending both on the assessment methodology used (e.g. "bottom up" versus "top down") and the assumptions made in the production stage $[41,42]$. However, the most extensive work on battery production [43] provides a value of $150-200 \mathrm{kgCO}_{2} / \mathrm{kWh}$. This leads to an excess of $4.2 \mathrm{tCO}_{2}$ for a $24 \mathrm{kWh}$ battery (the battery size for the initial Nissan Leaf models which would correspond to an $80-100 \mathrm{~km}$ range) which, assuming the same $\mathrm{CO}_{2}$ production emissions for the vehicle body and reduced production emissions for the EV drive train, will lead to a value similar to that shown in the earlier work by Ricardo. Hence, to more easily maintain compatibility with previous publications, the Ricardo production related $\mathrm{CO}_{2}$ emissions will be used in this work.

The production-related $\mathrm{CO}_{2}$ emissions are a product of the processes used to create the vehicle. Approximately $50 \%$ of the total energy used in the production of vehicles coming from the electricity grid [44] and as such this value will vary depending on the country of origin, and the expected year of manufacture. A vehicle constructed in a country which extensively uses coal-fired power stations will be more $\mathrm{CO}_{2}$ intensive than the same vehicle constructed in a country dominated by renewable energy sources. For example, the $\mathrm{CO}_{2}$ emissions from production of a vehicle produced in Japan would be higher than that same vehicle produced in the UK, due to the higher $\mathrm{CO}_{2}$ intensity in Japan.

Similarly, a vehicle constructed in 2040 will be less $\mathrm{CO}_{2}$ intensive (assuming a decarbonisation of the electricity production) than a vehicle constructed now. The UK has already observed strong grid decarbonisation with a reduction in 2017 of approximately $50 \%$ over 2010 levels [45]. This level of decarbonisation is higher than that originally estimated by the committee on Climate Change [12] but progress on decarbonisation beyond 2030 is uncertain. Beyond 2030 the carbon intensity projections split into two broad categories, with increased nuclear generation capability leading to a decarbonisation level of $80 \%$ and no new nuclear generation giving a decarbonisation of $30-50 \%$ [45]. Within this work the decarbonisation is assumed to be either $80 \%$, the UK government's expected level, or $50 \%$, a more conservative "worst case" scenario.

The two most popular full electric vehicles in the UK (discounting plug-in hybrids such as the Mitsubishi Outlander PHEV) are the Nissan Leaf and the BMW i3, which are manufactured in the UK and Germany respectively. However the Nissan Leaf is substantially the most popular, with sales of over 19,000 to up to the end of 2017 compared to 9000 for the BMW i3 [46]. For the purposes of this work, it is therefore assumed that vehicles are manufactured in the UK as this is the main manufacturing location of the Nissan Leaf. While Tesla models belong to the best-selling EV models worldwide, they are not the best-selling model in the UK. In addition, due to their positioning as a high end vehicle, they are not indicative of the typical mass-market ICE for EV swap.

\section{Results}

\subsection{Projections and impacts for EV adoption scenarios on on-road $\mathrm{CO}_{2}$ emissions}

As a preliminary step we calculated the on-road $\mathrm{CO}_{2}$ emissions under multiple different scenarios from 2014 to 2050. This is a fundamental first step as it both allows us to evaluate how the different scenarios would serve to meet the transport climate reduction targets set out in the Climate Change Act 2008 [5] and also form the basis of a combined on-road and embedded production $\mathrm{CO}_{2}$ emission value.

It was assumed that the current vehicle fleet would be steadily replaced with new vehicles, of which a certain proportion would be EVs. As the new vehicles are introduced, the $\mathrm{CO}_{2}$ emissions of the entire fleet would reduce as the older, less efficient vehicles are replaced by either more modern, lower-emitting ICE vehicles or by EVs. Previous research [47] on Norwegian transport emissions has shown the effect of temporal lag on $\mathrm{CO}_{2}$ emissions from vehicle transition rates.

It should be noted that the older vehicles are not necessarily being directly replaced by new vehicles. In reality first-hand vehicles would transition into second-hand vehicles, of which a proportion would be scrapped. However, the net result is that a certain number of new vehicles will be added to the fleet whilst a certain number of older vehicles will be scrapped. This transition is governed by Eq. (3). In addition, the stated $\mathrm{gCO}_{2} / \mathrm{km}$ metric for each new ICE vehicle would improve with each year from $130 \mathrm{gCO}_{2} / \mathrm{km}$ in 2015 to the predicted pan-European target of $95 \mathrm{gCO}_{2} / \mathrm{km}$ in 2021 [48]. However, as has been previously shown [39] the type approval stated efficiencies, derived from laboratory tests, underestimate the $\mathrm{CO}_{2}$ emissions when compared to on-road emissions tests and hence for the following calculations, the emissions have been increased to bring them in line with the more likely actual emissions. To account for this uncertainty in future ICE efficiency improvements, it is assumed that there are two scenarios for ICE vehicles representing a reduction to $60 \%$ and $80 \%$ of the 2011 values respectively.

In addition to ICE improvements in efficiency, there will be improvements in $\mathrm{CO}_{2}$ emissions intensity of the power which is being used to recharge EVs. Finally, in addition to the turnover of vehicles, there will be a steady increase in the number of vehicles on the road according to the forecasts by the Department for Transport's National Transport Model [35].

The EV adoption levels are either "Business as Usual" or the targeted EV goals of no new ICE vehicles by 2040. The ICE vehicles are either a reduction in $\mathrm{CO}_{2}$ emissions to $60 \%$ or $80 \%$ of current emissions levels. Similarly, the power grid decarbonisation is assumed to improve to either $50 \%$ or $80 \%$ over current rates with $80 \%$ being the expected decarbonisation and $50 \%$ a more conservative estimate. Each possibility for EV adoption rate, ICE efficiency improvement and power decarbonisation is combined and shown in table 1.

Fig. 3 presents the results of combining the different scenarios for 
Table 1

Eight scenarios combining the options for EV adoption, ICE efficiency improvement and power supply decarbonisation.

\begin{tabular}{|c|c|c|c|}
\hline Scenario & EV Adoption Rate & ICE $\mathrm{CO}_{2}$ Emission Intensity Reduction, 2014-2050 & Power Supply Decarbonization Rate, 2014-2050 \\
\hline 1 & Business as Usual & $60 \%$ & $50 \%$ \\
\hline 2 & Business as Usual & $60 \%$ & $80 \%$ \\
\hline 3 & Business as Usual & $80 \%$ & $50 \%$ \\
\hline 4 & Business as Usual & $80 \%$ & $80 \%$ \\
\hline 5 & Targeted & $60 \%$ & $50 \%$ \\
\hline 6 & Targeted & $60 \%$ & $80 \%$ \\
\hline 7 & Targeted & $80 \%$ & $50 \%$ \\
\hline 8 & Targeted & $80 \%$ & $80 \%$ \\
\hline
\end{tabular}

EV adoption, ICE efficiency improvements, and power supply decarbonisation.

Fig. 3 shows that the reduction in on-road $\mathrm{CO}_{2}$ emissions falls into three broad groups:

Group 3, the targeted EV adoption scenario coupled with the $80 \%$ decarbonisation of the electricity supply, shows the largest reduction in on-road $\mathrm{CO}_{2}$ emissions. Within this scenario, variation in ICE improvements has little effect on the total $\mathrm{CO}_{2}$ reduction, in part due to the increased adoption of EVs and concomitant lack of ICE vehicles with the predicted efficiency improvements.

Group 2, the targeted EV adoption scenario coupled with the $50 \%$ decarbonisation of the electricity supply, shows the second largest reduction. In this scenario, similarly to group 3 , the increased adoption of EVs means that increased ICE efficiencies have little overall impact but the lack of decarbonisation compared to group 3 leads to increased overall $\mathrm{CO}_{2}$ emissions.

Finally, group 1 shows that with a greatly reduced level of EV uptake, it is the improvements in ICE efficiency that will deliver the greatest improvements in $\mathrm{CO}_{2}$ emissions.

Fig. 3 also shows that there is minimal difference between any of the scenarios before 2030. Up to this point the reduction in $\mathrm{CO}_{2}$ for the vehicle fleet is being driven by the turnover of ICE vehicles with older vehicles being replaced with newer, more efficient models.

\subsection{Combined embedded production and On-Road $\mathrm{CO}_{2}$ emissions}

In addition to on-road $\mathrm{CO}_{2}$ emissions, it is also necessary to look at the embedded $\mathrm{CO}_{2}$ emissions from vehicle production.

In many life cycle assessments of EVs and ICEs, the effect of embedded $\mathrm{CO}_{2}$ is ameliorated through applying the embedded $\mathrm{CO}_{2}$ over the full life time of the vehicle. Whilst this is a valid approach in determining whether a vehicle is carbon neutral or not, it is not a valid approach when determining the overall $\mathrm{CO}_{2}$ impact of a policy. The emitted $\mathrm{CO}_{2}$ from production will be emitted over the course of a vehicle's manufacture, not over the course of its lifetime; hence the impact of $\mathrm{CO}_{2}$ will occur at the time of manufacture. The argument to include production $\mathrm{CO}_{2}$ at the time of manufacture is even more striking from an analysis of the physical processes behind the $\mathrm{CO}_{2}$ effect as a greenhouse gas, as the radiative forcing of $\mathrm{CO}_{2}$ will have an impact from the time of emission [49].

In Fig. 4 we can see the impact of adding emitted $\mathrm{CO}_{2}$ from vehicle production to the on-road $\mathrm{CO}_{2}$ emissions. In addition, the effect of a decarbonisation of the electricity grid by $50 \%$ over 2014 levels is demonstrated. The decarbonisation [50] predicted for the UK will lead to a strong reduction in the embedded $\mathrm{CO} 2$ associated with the manufacture of each vehicle. Non electricity dependent production processes are assumed, due to a lack of relevant studies, to follow the same trend.

In a similar fashion to the on-road $\mathrm{CO}_{2}$, there is little difference between the two scenarios before 2030, in either the on-road $\mathrm{CO}_{2}$ or the embedded $\mathrm{CO}_{2}$. After 2030 the data begins to strongly diverge with the Targeted Scenario offering a reduction in total emitted $\mathrm{CO}_{2}$ of approximately $20 \mathrm{MtCO}_{2}$ by 2050 . In addition, the assumption of a $50 \%$ decarbonisation of the carbon intensity used in EV and ICE production, leads to a larger reduction in total emitted $\mathrm{CO}_{2}$ by the passenger vehicle transport sector.

In Fig. 5 the relative proportions for the main transport emissions for the BAU and Targeted scenarios at 50\% decarbonisation, as well as a third scenario with $80 \%$ decarbonisation. In each figure the $\mathrm{CO}_{2}$ emissions are split into either embedded or on-road $\mathrm{CO}_{2}$ and then further split by vehicle type, either ICE or EV.

For both the Targeted and Targeted plus $80 \%$ decarbonisation scenarios the largest single source of $\mathrm{CO}_{2}$ emissions in 2050 come from the production of the vehicle. This is in contrast to the case currently where the vast majority of $\mathrm{CO}_{2}$ is emitted from the on-road portion of the transport $\mathrm{CO}_{2}$ emissions.

It can be seen that for the Targeted plus $80 \%$ decarbonisation scenario, the goal of $20 \%$ of $1990 \mathrm{CO}_{2}$ emission levels will be reached.

If production decarbonisation were not included in the three uptake scenarios then a much greater proportion of the $\mathrm{CO}_{2}$ emissions for both the accelerated and targeted EV growth scenarios would be embedded

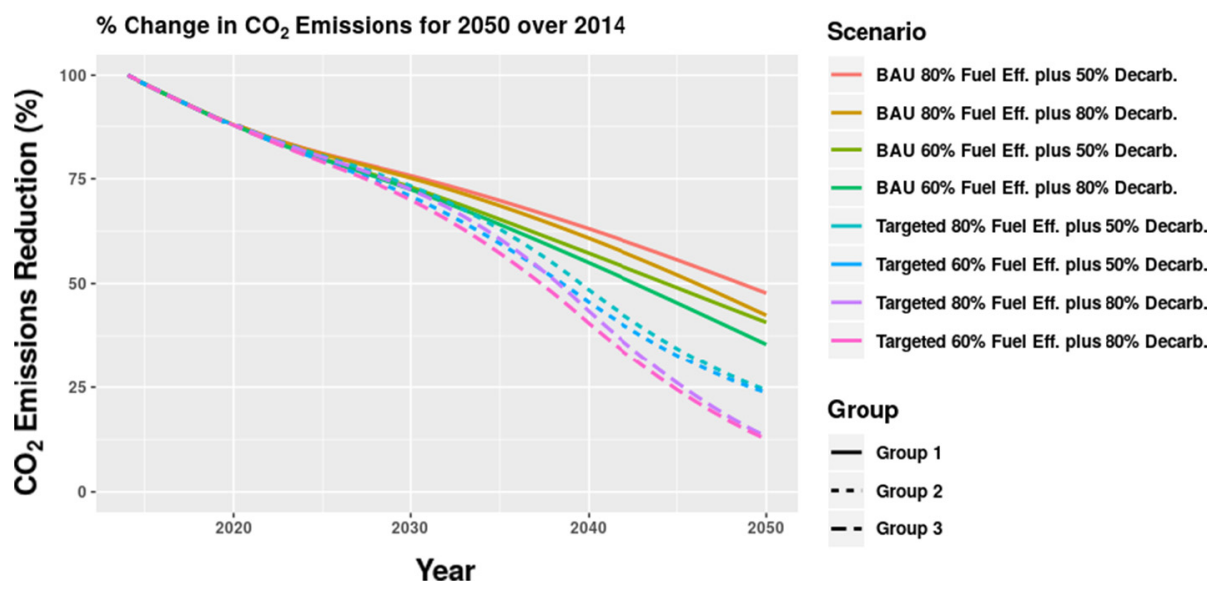

Fig. 3. Level of carbon reduction within the private vehicle sector for scenario variations. 


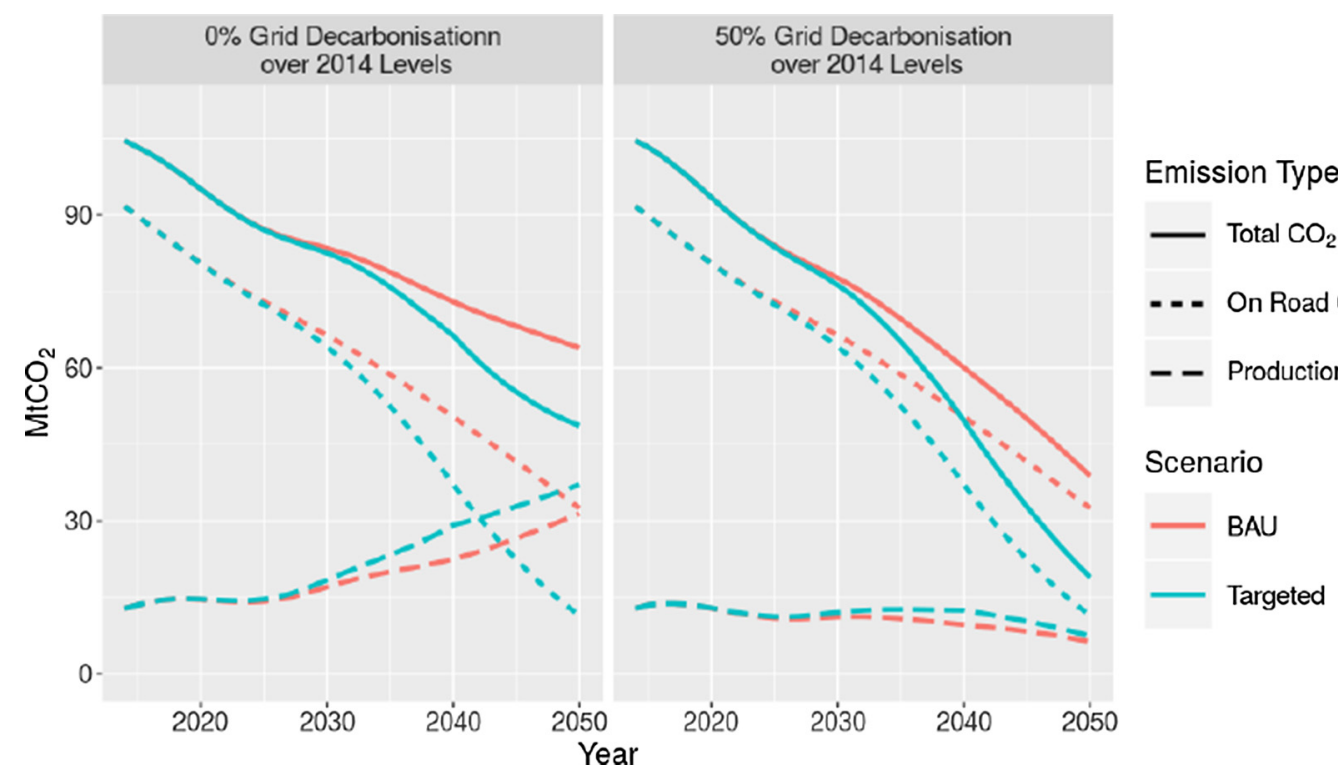

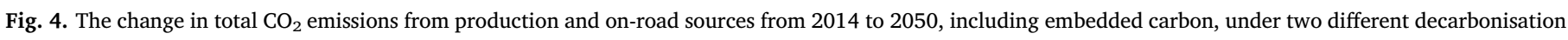
and EV uptake scenarios.

in the productions of EVs. The impact of limited decarbonisation on embedded $\mathrm{CO}_{2}$ would lead to overall $\mathrm{CO}_{2}$ emissions at approximately $50 \%$ of the 2014 levels. This is substantially higher than is required by the Climate Change Act 2008.

\section{Discussion}

Across the world the question of how fast transport electrification can contribute to climate change mitigation targets is of high interest, given the challenge of steep decarbonisation required to keep global warming below $1.5^{\circ} \mathrm{C}$ or $2{ }^{\circ} \mathrm{C}$ [51]. Our analysis shows that under all possible adoption scenarios, increased $\mathrm{EV}$ adoption will only show a significant benefit compared to the BAU case after 2030 and it will only lead to a change that is greater than $10 \%$ after 2040 (Fig. 5). Prior to this, the improvement in transport $\mathrm{CO}_{2}$ emissions will be driven by the natural transition to a newer vehicle fleet, with the efficiency improvements this entails. Past 2040 , it is only the $100 \%$ EV sales by 2040 ambition that will achieve the necessary reduction in on-road $\mathrm{CO}_{2}$ emissions as stipulated in the 2008 Climate Change Act. Without the 2040 ambition it is predicted that the total on-road $\mathrm{CO}_{2}$ emissions in
2050 will be $32 \mathrm{MtCO}_{2}$. This is substantially short of the required reduction to $18 \mathrm{MtCO}_{2}$ corresponding to $20 \%$ of 1990 emission levels.

However, this assumes that the on-road $\mathrm{CO}_{2}$ emissions are the only metric which is applicable. The Climate Change Act does not specify which sectors must provide the necessary reduction in $\mathrm{CO}_{2}$ only that the overall $\mathrm{CO}_{2}$ level must be reduced by $80 \%$ on 1990 levels. Therefore it would be disingenuous to base the $\mathrm{CO}_{2}$ emissions reduction calculations on only the on-road $\mathrm{CO}_{2}$. Fig. 5 shows the result of including both ICE and $\mathrm{EV}$ embedded $\mathrm{CO}_{2}$ emissions in the manufacture of vehicle. It can be seen that in both the Targeted and Targeted plus $80 \%$ decarbonisation scenario, the largest source of $\mathrm{CO}_{2}$ emissions comes from the production of EVs. The on-road carbon footprint of the ICE vehicles is substantially reduced due to the turnover of vehicles past the 2040 target coupled with the improvements in efficiency for the new ICE vehicles, with the embedded production $\mathrm{CO} 2$ of ICE reduced to zero due to the same target. On-road $\mathrm{CO}_{2}$ for the EVs is also much smaller because of the decarbonisation of the electricity supply. If embedded $\mathrm{CO} 2$ is included in the reduction calculations (and also included in the 1990 carbon target) then only the targeted plus $80 \%$ decarbonisation scenario will meet the 2050 targets, with a final total $\mathrm{CO}_{2}$ emission of 16.5
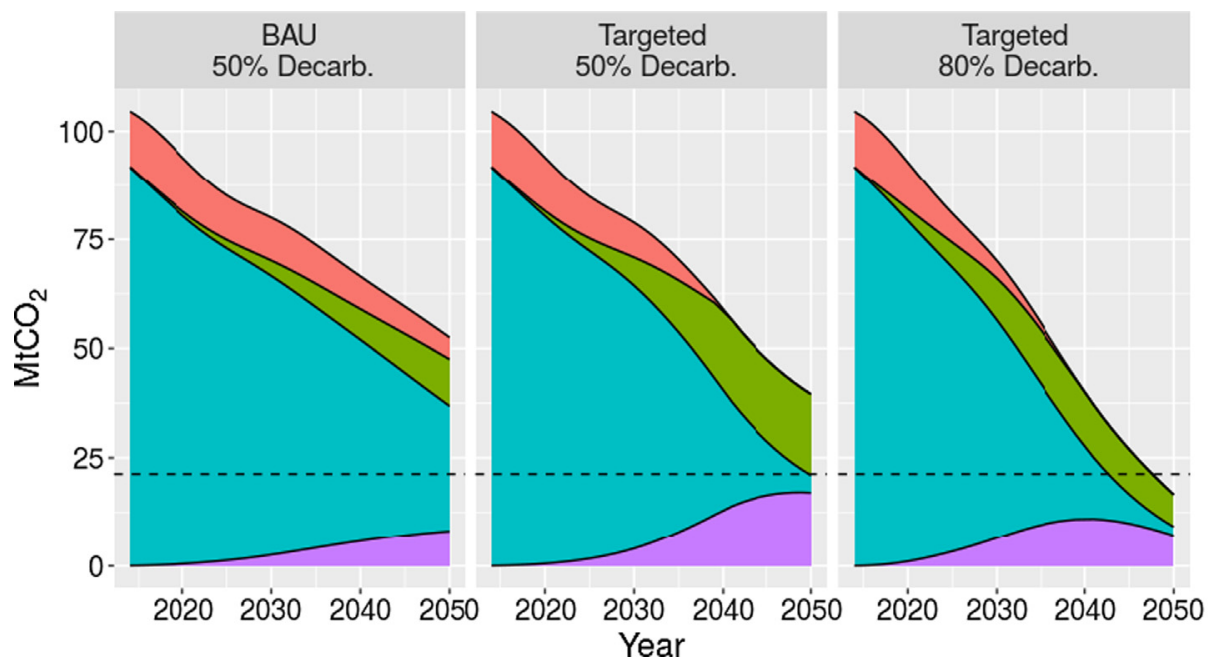

\section{Emission Type}

Embedded ICE $\mathrm{gCO}_{2}$

Embedded $\mathrm{EV} \mathrm{gCO}_{2}$

ICE On-Road gCO

EV On-Road $\mathrm{gCO}_{2}$

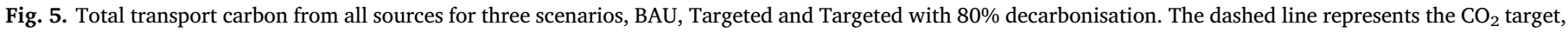
set at $20 \%$ of 1990 levels. 
$\mathrm{MtCO}_{2}$. The targeted plus $50 \%$ decarbonisation scenario will show a final total emission of $\sim 40 \mathrm{MtCO}_{2}$ (approximately $35 \%$ of 1990 levels) with the BAU Scenario substantially higher than that. This remains over $15 \mathrm{MtCO}_{2}$ more than the $20 \%$ of 1990 levels required.

From Fig. 5 it can be seen that the vast majority of $\mathrm{CO}_{2}$ emissions reduction in the transport sector would be delivered simply by the replacement of old ICE vehicles with new, more efficient vehicles. It was shown that whilst improved efficiency in new build ICE vehicles coupled with the year on year turnover of vehicles is the largest driver in near term $\mathrm{CO}_{2}$ reduction, it will not provide the needed mid to long term results. Achieving a lasting long term reduction in $\mathrm{CO}_{2}$ emissions will be dependent on a greatly increased EV uptake coupled with an intensive decarbonisation of the power supply used in both the refuelling of EVs and also their production. Assuming that the current technological trends in $\mathrm{CO}_{2}$ reduction for ICE/EV vehicles and their production will continue is not an unreasonable assumption, but it is also a wager on future technological improvements which could lead to a transport policy based on vehicle and production efficiencies which never arrive. For such transitions it is vital to understand not only the environmental effects of a move to EVs, but also how this will affect the costs, revenues, and business structures for EVs throughout their value and life cycle chain.

It should be stressed that the conclusions reached in this paper are dependent on a large series of assumptions on, for example, future vehicle numbers, vehicle scrappage rates, future improvements in vehicle efficiency and decarbonisation of the electric grid. Where possible these assumptions have been justified with reference to literature or statistics but a certain level of judgment has been used in balancing across scenarios. The numbers presented are also drawn from the UK case, they would not be representative of France, for example, where the $\mathrm{CO}_{2}$ intensity of the electricity supply is significantly lower.

A final consideration is the issue of global and local air pollution. For a number of years now, it has been known that the Euro standard emissions for both petrol and diesel vehicles have resulted in some vehicle types emitting much more pollutants and $\mathrm{CO}_{2}$ in real-world driving than is expected from the actual limits specified for the tests. This may, in some way, trigger policies that aim to reduce vehicle emissions for health purposes as well as reducing $\mathrm{CO}_{2}$ [52]. Moreover, if conformance to the emissions in tests and those in real-world driving move closer to $1: 1$ following the next round of negotiations for post Euro 6 emissions regulations from 2021, it may provide a better defined pathway for motor manufacturers to offer more EV models and at a more affordable price. Coupled with this is the trend for cities to look towards introducing clean air zones where older, polluting vehicles will be financially penalised for being in these zones.

\section{Conclusions}

Our analysis shows that whilst EVs, coupled with a decarbonised power grid, are the best option for achieving long-term wide ranging decarbonisation of the transport system, they will show little impact in the short term. The effects of accelerated EV adoption will only become significantly apparent post 2030 as the older, less efficient ICE vehicles are aged out and this is not only based on the relatively slow diffusion of new vehicles into the vehicle fleet but, more relevantly, in up-front $\mathrm{CO}_{2}$ emissions from vehicle production when the electricity sector has not yet been fully decarbonized. However, mitigation effects from onroad usage will become significant after 2030 as both $\mathrm{CO}_{2}$ emissions from on-road usage and from vehicle production decrease further. A key-point to take away from this work is that there exists a natural lag between the implementation of any policy to drive EV adoption and its subsequent effect on $\mathrm{CO}_{2}$ emissions on the transport fleet. Policies should be implemented with the understanding that they may not produce meaningful results for potentially a decade or more. Hence, to achieve mid-term climate targets, it is important to invest now in the electrification of passenger fleets, e.g. by public procurement, efficiency standards, improved information provision [53], purchase taxes on non-electric vehicles, and charging infrastructures.

Whilst EVs will not provide a solution for near-term $\mathrm{CO}_{2}$ mitigation, it will be possible to achieve the short term $\mathrm{CO}_{2}$ emission reduction goals through demand-side solutions, rather than simply focussing on the supply side solutions implied by EVs. Whilst the majority of change in on-road $\mathrm{CO}_{2}$ emissions (for light duty passenger vehicles especially) has come from technological improvements, demand side solutions to either reduce travel demand or induce a modal shift hold promise, often also for quality of life [54]. Demand side solutions of this nature can be implemented alongside the technological solutions and will provide a multiplier effect that will not be dependent on possible future technologies.

\section{Acknowledgements}

The researchers gratefully acknowledge the on-going support of the UK's Engineering and Physical Sciences Research Council (EPSRC) through the following funding awards: LC TRANSFORMS (Low Carbon Transitions of Fleet Operations in Metropolitan Sites EP/N010612/1); iBUILD (Infrastructure BUsiness models, valuation and Innovation for Local Delivery EP/K012398/1) ReLiB (Recycling of Li-Ion Batteries) The Faraday Institution (FIRG005) and CESI (Centre for Energy Systems Integration EP/P001173/1).

\section{References}

[1] Kahn Ribeiro S, Figueroa MJ, Creutzig F, Dubeux C, Hupe J, Kobayashi S. Chapter 9 - Energy End-Use: Transport. Global Energy Assessment - Toward a Sustainable Future. Cambridge University Press, Cambridge, UK and New York, NY, USA and the International Institute for Applied Systems Analysis, Laxenburg, Austria; 2012. pp. 575-648.

[2] Creutzig F. Evolving narratives of low-carbon futures in transportation. Transp Rev Routledge 2016;36:341-60.

[3] Heidrich O, Reckien D, Olazabal M, Foley A, Salvia M, de Gregorio Hurtado S, et al. National climate policies across Europe and their impacts on cities strategies. J Environ Manage 2016;168:36-45.

[4] Heidrich O, Hill GA, Neaimeh M, Huebner Y, Blythe PT, Dawson RJ. How do cities support electric vehicles and what difference does it make? Technol Forecast Soc Change 2017;123:17-23.

[5] Government HM. Climate Change Act 2008 [Internet]. 2008. Available: https:// www.legislation.gov.uk/ukpga/2008/27/contents.

[6] Committee on Climate Change. Progress report 2016: meeting carbon budgets. CCC; 2016.

[7] Capros P, De Vita A, Tasios N, Siskos P, Kannavou M, Petropoulos A, et al. energy, transport and GHG emissions -trends to 2050. Eur Community 2016;2016:27. https://doi.org/10.2833/9127.

[8] DfT. Greenhouse gas emissions by transport mode: United Kingdom, 2003-2016, [Internet]. Table ENV0201. 201Available: https://www.gov.uk/government/ statistical-data-sets/env02-greenhouse-gas-emissions.

[9] BEIS. Clean Growth Strategy [Internet]. 2017. Available: https://www.gov.uk/ government/publications/clean-growth-strategy.

[10] Office for Low Emission Vehicles. The Road to Zero. Department of Transport (DfT); 2018 Jul.

[11] DfT. Ultra-low emission vehicles (ULEVs) registered for the first time (VEH0170) [Internet]. 2018. Available: https://www.gov.uk/government/uploads/system/ uploads/attachment_data/file/715998/veh0170.ods.

[12] Committee on Climate Change. Progress in preparing for climate change. Committee on Climate Change; 2015 Jun.

[13] Hofmann J, Guan D, Chalvatzis K, Huo H. Assessment of electrical vehicles as a successful driver for reducing CO2 emissions in China. Appl Energy 2016;184:995-1003.

[14] Orsi F, Muratori M, Rocco M, Colombo E, Rizzoni G. A multi-dimensional well-towheels analysis of passenger vehicles in different regions: primary energy consumption, CO2 emissions, and economic cost. Appl Energy 2016;169:197-209.

[15] Alam MS, Hyde B, Duffy P, McNabola A. Assessment of pathways to reduce CO2 emissions from passenger car fleets: Case study in Ireland. Appl Energy 2017; 189:283-300.

[16] Harvey LDD. Resource implications of alternative strategies for achieving zero greenhouse gas emissions from light-duty vehicles by 2060. Appl Energy 2018;212:663-79.

[17] Vikström H, Davidsson S, Höök M. Lithium availability and future production outlooks. Appl Energy 2013;110:252-66.

[18] eurostat. Energy, transport and environment indicators. eurostat; 2017 Nov.

[19] Schäfer A. Structural change in energy use. Energy Policy 2005;33:429-37.

[20] Nanaki EA, Koroneos CJ. Climate change mitigation and deployment of electric vehicles in urban areas. Renewable Energy 2016;99:1153-60. 
[21] Schipper L. Automobile use, fuel economy and CO2 emissions in industrialized countries: Encouraging trends through 2008? Transp Policy 2011;18:358-72.

[22] European Commission. Regulation Of The European Parliament And Of The Council setting emission performance standards for new passenger cars and for new light commercial vehicles as part of the Union's integrated approach to reduce $\mathrm{CO} 2$ emissions from light-duty vehicles and amending Regulation (EC) No 715/2007 [Internet]. 2017. Available: http://eur-lex.europa.eu/legal-content/EN/ALL/?uri = CELEX:52017PC0676\&qid =1518371681956.

[23] Reckien D, Flacke J, Olazabal M, Heidrich O. The Influence of drivers and barriers on urban adaptation and mitigation plans-an empirical analysis of European cities. PLOS ONE 2015;10:e0135597.

[24] DECISION No 406/2009/EC OF The European Parliament And Of The Council of 23 April 2009 on the effort of Member States to reduce their greenhouse gas emissions to meet the Community's greenhouse gas emission reduction commitments up to 2020. Official Journal of the European Union. 2009;L140: 136-148.

[25] Sharma Ashish, Strezov Vladimir. Life cycle environmental and economic impact assessment of alternative transport fuels and power-train technologies. Energy 2017;133:1132-41.

[26] Papson A, Creutzig F, Schipper L. Compressed Air Vehicles: Drive-Cycle Analysis of Vehicle Performance, Environmental Impacts, and Economic Costs. Transp Res Rec. SAGE Publications Inc; 2010;2191: 67-74.

[27] Penna CCR, Geels FW. Climate change and the slow reorientation of the American car industry (1979-2012): An application and extension of the Dialectic Issue LifeCycle (DILC) model. Res Policy 2015;44:1029-48.

[28] Hardman Scott. Understanding the impact of reoccurring and non-financial incentives on plug-in electric vehicle adoption - a review. Transp Res Part A: Policy Practice 2019;119:1-14.

[29] Department of Energy and Climate Change (DECC). The carbon plan: Delivering our low carbon future. HM Government; 2011 Dec.

[30] Department for Transport (DfT). Local Sustainable Transport Fund annual report 2011 to 2012. 2013 Jun.

[31] Committee on Climate Change. Sectoral Scenarios for the Fifth Carbon Budget [Internet]. CCC; 2015 Nov. Available: https://www.theccc.org.uk/publication/ sectoral-scenarios-for-the-fifth-carbon-budget-technical-report/.

[32] DEFRA, DFT. Air quality plan for nitrogen dioxide (NO2) in UK (2017) [Internet]. 2017. Available: https://www.gov.uk/government/publications/air-quality-planfor-nitrogen-dioxide-no2-in-uk-2017.

[33] Serradilla J, Wardle J, Blythe P, Gibbon J. An evidence-based approach for investment in rapid-charging infrastructure. Energy Policy 2017;106:514-24.

[34] DfT. Road Traffic Forecasts 215. DfT; 2015.

[35] Department for Transport (DfT). Anonymised MOT tests and results [Internet]. 2017. Available: https://data.gov.uk/dataset/e3939ef8-30c7-4ca8-9c7cad9475cc9b2f/anonymised-mot-tests-and-results.

[36] Chatterton T, Barnes J, Wilson RE, Anable J, Cairns S. Use of a novel dataset to explore spatial and social variations in car type, size, usage and emissions. Transp Res Part D: Trans Environ 2015;39:151-64.

[37] Blythe PP, Hill DG, Huebner DY, Suresh V, Austin J, Gray L, et al. North East
England electric vehicle and infrastructure trials. World Electric Vehicle J Multidiscipl Digital Publishing Institute 2012;5:856-65.

[38] Robinson AP, Blythe PT, Bell MC, Hübner Y, Hill GA. Analysis of electric vehicle driver recharging demand profiles and subsequent impacts on the carbon content of electric vehicle trips. Energy Policy 2013;61:337-48.

[39] ICCT. On-road testing of CO2 and exhaust emissions from Euro 6 passenger cars in the EU: Technical Report [Internet]. 2016. Available: https://www.theicct.org/ sites/default/files/publications/Euro\%206\%20on-road\%20testing_ICCT_technical \%20report 20160929.pdf.

[40] Ricardo. Preparing for a Life cycle CO2 Measure. LowCVP; 2011.

[41] Miotti M, Supran GJ, Kim EJ, Trancik JE. Personal vehicles evaluated against climate change mitigation targets. Environ Sci Technol. American Chemical Society 2016;50:10795-804.

[42] Hawkins TR, Singh B, Majeau-Bettez G, Strømman AH. Comparative environmental life cycle assessment of conventional and electric vehicles. J Ind Ecol 2013;17:53-64.

[43] Romare M, Lisbeth D. The life cycle energy consumption and greenhouse gas emissions from lithium-ion batteries. IVL Swedish Environmental Research Institute 2017.

[44] Sullivan, J L, Burnham, A, Wang, M, and Energy Systems. Energy-consumption and carbon-emission analysis of vehicle and component manufacturing.. United States: N. p., 2010. Web. doi:10.2172/993394.

[45] Committee on Climate Change. Reducing UK emissions. 2018 Progress Report to Parliament. Committee on Climate Change; 2018 Jun.

[46] Department for Transport (DfT). Licensed vehicles by make and model: Great Britain and United Kingdom [Internet]. 2018. Available: https://www.gov.uk/ government/uploads/system/uploads/attachment_data/file/715986/veh0120.ods.

[47] Fridstrøm L. From innovation to penetration: Calculating the energy transition time lag for motor vehicles. Energy Policy. 2017;108:487-502.

[48] SMMT. NEW CAR CO2 REPORT 2017. SMMT; 2017.

[49] Forster P, Ramaswamy V, Artaxo P, Berntsen T, Betts R, Fahey DW, et al. Changes in atmospheric constituents and in radiative forcing. Chapter 2. Climate Change 2007 The Physical Science Basis. 2007.

[50] BEIS. Digest of UK Energy Statistics 2017. Department for Business, Energy \& Industrial Strategy; 2017.

[51] IPCC, 2014: Climate Change 2014: Synthesis Report. Contribution of Working Groups I, II and III to the Fifth Assessment Report of the Intergovernmental Panel on Climate Change [Core Writing Team, R.K. Pachauri and L.A. Meyer (eds.)]. IPCC, Geneva, Switzerland, $151 \mathrm{pp}$.

[52] Giardullo P, Sergi V, Carton W, Kenis A, Kesteloot C, Kazepov Y, et al. Air quality from a social perspective in four European metropolitan areas: research hypothesis and evidence from the SEFIRA project. Environ Sci Policy. 2016;65:58-64.

[53] Neaimeh M, Hill GA, Hübner Y, Blythe PT. Routing systems to extend the driving range of electric vehicles. IET Intel Transport Syst 2013;7:327-36.

[54] Creutzig F, Fernandez B, Haberl H, Khosla R, Mulugetta Y, Seto KC. Beyond technology: demand-side solutions for climate change mitigation. Annu Rev Environ Resour. Annual Reviews 2016;41:173-98. 